\title{
Global And Regional Cancer Epidemiology: According To World Cancer Report 2012 And Others.
}

\section{- - - - - Mohiuddin Alamgir --------------------------}

ABSTRACT:

The International Agency on Cancer (IARC) has initiated World Cancer Report 2012 in 2014. The report estimates the worldwide incidence and mortality for 27 major cancers and for all cancers combined for 2012 and is available in the GLOBOCAN series of the International Agency for Research on Cancer. Overall, there were 14.1 million new cases and 8.2 million deaths in 2012. The most commonly diagnosed cancers were lung (1.82 million), breast (1.67 million), and colorectal (1.36 million); the most common causes of cancer death were lung cancer (1.6 million deaths), liver cancer (745,000 deaths), and stomach cancer (723,000 deaths). In Pakistan, there are over 1.4 million cancer patients. Annually there are 139,200 new cancer cases and 101,600 deaths. Incidences of cancers are different in different parts of Pakistan as depicted by reports generated by two major cancer registries in the country.

Keywords: GLOBOCAN, incidence, cancer, global estimates, mortality.

\section{INTRODUCTION:}

The world body for cancer estimation (International Agency for Research on Cancer, IARC) has initiated the World Cancer Report 2012 in 2014. The report estimates the global incidence and mortality for 27 major cancers and for all cancers combined for the year 2012 and is accessible at the GLOBOCAN series of the IARC. According to this report there were on the whole 14.1 million new cases of cancer and 8.2 million deaths in 2012. In order of frequency those were of lung (1.82 million), breast (1.67 million), and colorectal (1.36 million), respectively. Highest cancer mortality belonged to the lung cancer (1.6 million deaths), liver cancer (745,000 deaths), and stomach cancer $(723,000$ deaths), respectively ${ }^{1}$. In Pakistan, although there is no centralized data for cancer incidence in its population, there exist various hospital-based cancer registries. Data published by these registries show frequencies of different cancers treated at these facilities. This gives us some idea about the cancer status in Pakistan despite variation from region to region.

\section{METHODOLOGY:}

Search engine of Google was utilized with various keywords and phrases to search articles related to worldwide cancer epidemiology. Keywords and phrases such as cancer incidence, cancer mortality, global cancer prevalence, world cancer report, Globocan etc., were used. A total of 40 articles including successive world cancer reports, reviews, original articles and textbooks were selected. However, the major content of this review is based on the fifth version of GLOBOCAN and its sources for estimating cancer incidence and mortality for 2012 in 184 countries. The same can be

I Mohiuddin Alamgir

Department of Pathology,

Bahria University Medical \& Dental College, Karachi.

I Email: doc_alamgir@yahoo.com

Received: 15-05-2018

I Accepted: 26-09-2018

ᄂ ------------------1 accessed via the GLOBOCAN homepage (http://globo can.iarc.fr).

\section{LITERATURE REVIEW:}

The IARC data and its sources were reviewed and are briefly described here. The data covered global incidences and mortality for 27 common cancers for the year 2012 in world continents and regions ${ }^{1-7}$.

Cancer is a grave and mounting problem in many parts of the globe, a fact that has been reflected by successive world cancer reports and other epidemiological studies ${ }^{8-19}$. IARC, the committed cancer agency of the World Health Organization, has initiated the World Cancer Report 2012

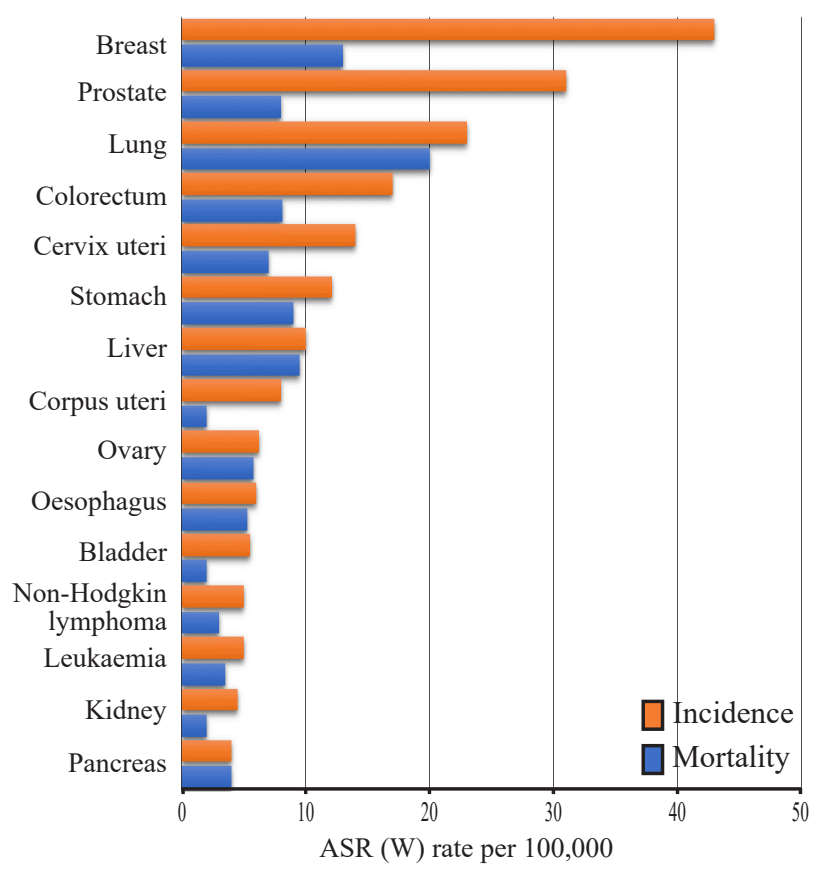

Figure 1. Estimated ASRs for incidence and mortality rates: male/ female combine

[Source: Adapted and Modified from World Cancer Report 2012] 
on $3^{\text {rd }}$ February 2014. This was the work of over 250 chief scientists from more than forty countries unfolding multiple features of cancer research and control ${ }^{1}$. According to this report the world cancer incidence rose to 14 million cases. This number is likely to rise to an annual 19.3 million by 2025. Over the same period, cancer deaths are anticipated to go up from an estimated 8.2 million to 13 million annually. The world's most frequent cancer was the lung cancer (13\% of total cancers). Breast cancer occupied the second position among all cancers at $11.9 \%$ only to be followed by colorectal cancer at $9.7 \%$ and prostate cancer at $7.9 \%$ Fig. $1^{1,20,21}$.

In men most frequent cancers included lung cancer $(16.7 \%)$, prostate cancer (15\%) and colorectal carcinoma
$(10 \%)$. In women the commonest was the breast cancer $(25.5 \%)$, trailed by those of colorectum $(9.2 \%)$ and lung (8.7\%). Age-standardized incidence rates (ASRs) per 100,000 of population, when considered for both genders combine, were topped by breast cancer at 43.1 followed by prostate at 30.7 and lung ${ }^{1}$.

The rank-wise distribution of the 15 most frequent cancers are shown for males (Figure 2a) and females (Figure 2b) in more developed and underdeveloped areas of the world. In men overall the most common cancer is that of lung but the same cancer stands as second in more developed countries being preceded by prostate cancer. Cancers of lung, liver and stomach represent $40 \%$ of new cancers and $48 \%$ of a

More developed regions

$$
\begin{array}{r}
\text { Lung } \\
\text { Prostate } \\
\text { Colerectum } \\
\text { Stomach } \\
\text { Liver } \\
\text { Bladder } \\
\text { Oesophagus }
\end{array}
$$

Non-Hodgkin lymphoma

$$
\begin{array}{r}
\text { Kidney } \\
\text { Leukaemia } \\
\text { Lip, oral cavity }
\end{array}
$$

Pancreas

Brain, nervous system

Larynx

Melanoma of skin

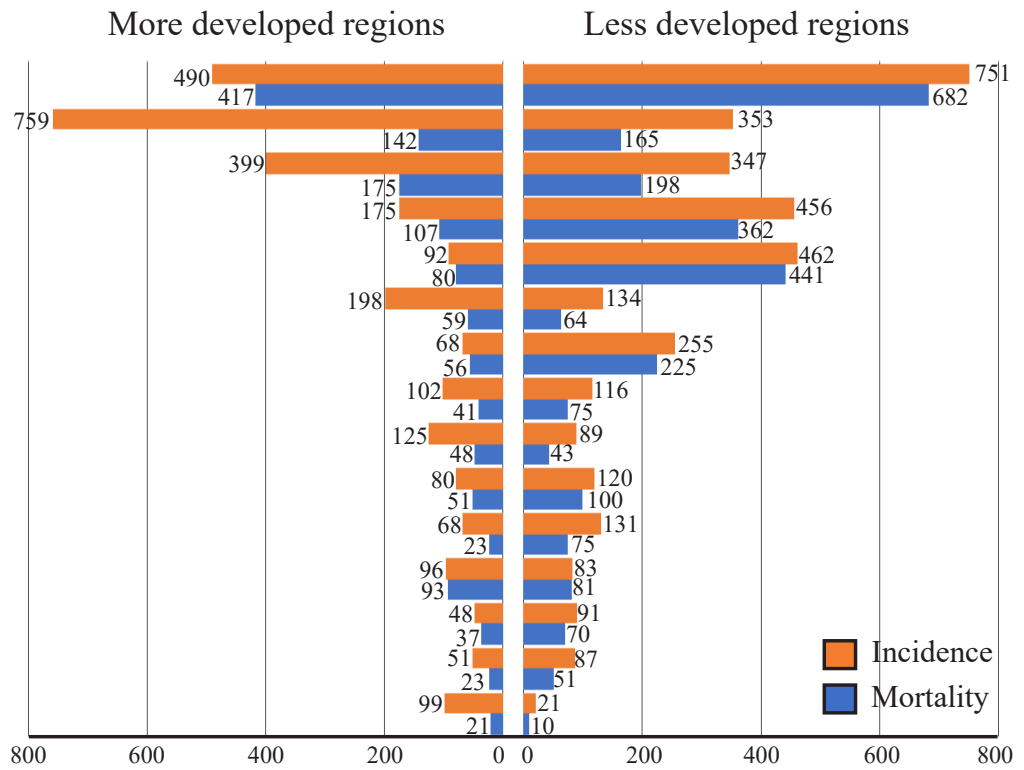

Figure 2a. Estimated cancer incidence and mortality in men [Reproduced from Ferlay et al., 2015].

b

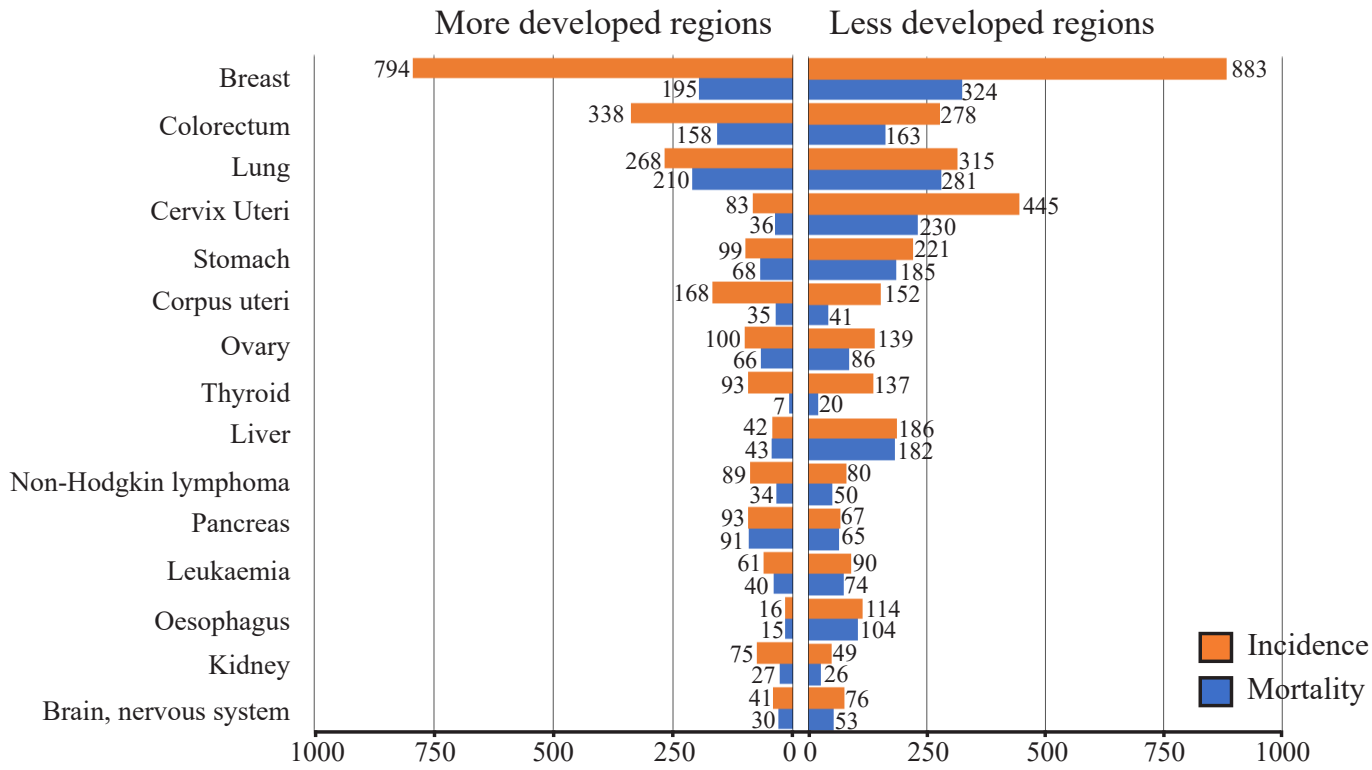

Figure 2b. Estimated cancer incidence and mortality in women [Reproduced from Ferlay J et al., 2015]. 


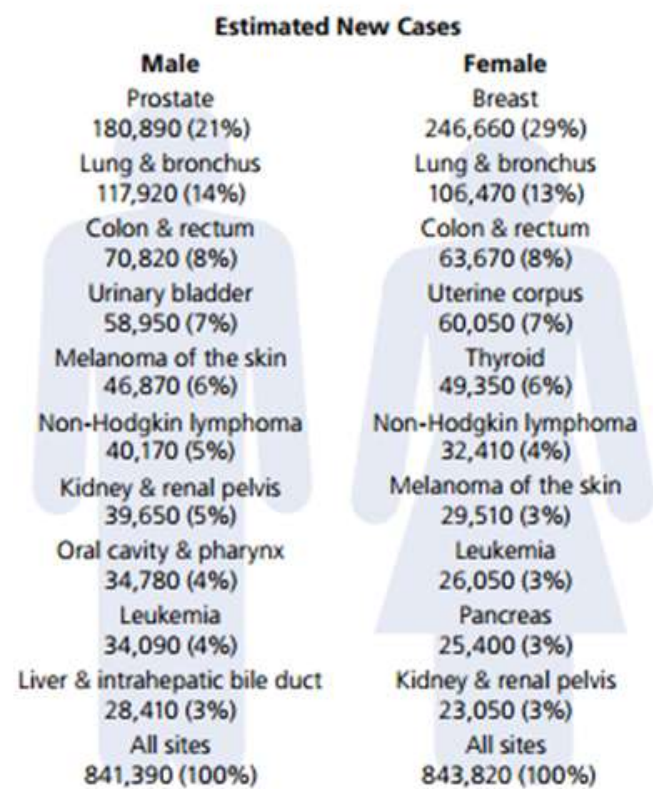

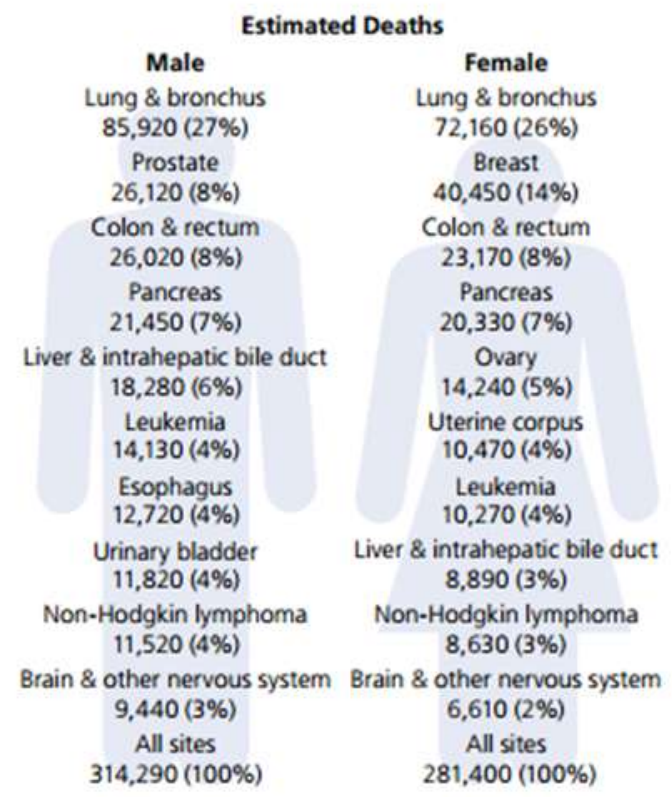

Figure 3. Predicted new cancer cases and deaths in America for the year 2016 [Source: Adapted from® 2016, American Cancer Society, Inc., Surveillance Research]

cancer deaths among males in less developed countries. Breast cancer is the commonest cancer in women, however, more cases occur in under-developed than developed regions. Similarly, cervical cancer, which is the second most frequent cancer in less developed regions, stands as $11^{\text {th }}$ in developed countries. As far as cancer related deaths in women are concerned, lung cancer tops the list in developed regions while in less developed regions breast cancer leads ${ }^{1,20-23}$.

The predicted growth of various cancers is largely based on demographic changes in population and it did not take into account the associated risk factors. If both are considered simultaneously, the world projected number of new cancer cases would be likely to reach up to 25 million by $2025^{24}$.

\section{Cancer Incidence in United States of America (USA)}

The American cancer society published in its report the number of new cancer cases and deaths by sex for the year 2016 as shown in figure 3. These estimates were based on 1998-2012 incidence data as reported by various agencies. Lung cancer ranked second amongst both sexes while 224,390 new lung cancer cases were expected in 2016. The same was responsible for more deaths than any other cancer in both genders. Among American women breast cancer was the most frequent cancer which had been projected to be diagnosed in 246,660 women ranking second as a cause of cancer death in women. Adenocarcinoma of prostate gland was expected to be the most common cancer in males, 180,890 new cases were predicted in 2016. For Oropharyngeal cancers incidence is twice as high in males as compared to females. 48,330 new cases and 9,570 deaths from these cancers were expected in 2016. Incidence trends for this cancer showed that from 2003 to 2012 the incidence rate among whites increased by $1.3 \%$ per year in men while it remained stable in women. This increase has been attributed to cancers of oropharynx, base of the tongue and tonsils that are related to HPV infection ${ }^{25}$.

\section{Cancer incidence in Europe}

IARC population data sheet for European region shows an estimated 3,714,700 new cases and 1,932,800 deaths occurred in 2012 (figure 4).

ASRs for three most common cancers of breast, colorectum and lung were 66.5, 28.2 and 28.8, respectively. ASRs for three common cancers in men were: prostate (58.5), Lung (46.9) and colorectum (35.6). Mortality figure for same cancers were 11.5, 40.3 and 15.7, respectively. ASRs for three commonest cancers in women were: breast (66.5), colorectum (22.6), lung (14.4) and corresponding mortality rates were 16.0, 9.7 and 11.3 respectively. For lip and oral cavity cancer 45567 (2.3\%) cases with an ASR of 7.1 and 18642 deaths (1.7) with an ASR of 2.9 has been reported ${ }^{7,26}$.

\section{Cancer incidence in South-East Asia}

In South East Asia 1,724,300 new cancer cases and 1,171,300 deaths were recorded. The three most common cancers were breast, cervix uteri and lung having ASRs of 27.8, 20.5 and 10.5 , respectively (figure 5).

ASRs for three common cancers in men were: Lung (15.7), lip and oral cavity (8.9), colorectum (8.9), with mortality ASRs of 14.2, 5.7 and 6.3, respectively. ASRs for three commonest cancers in women were: breast (27.8), cervix uteri (20.5), colorectum (6.3) and corresponding mortality ASRs were 12.9, 11.3 and 4.4, respectively ${ }^{1}$. 


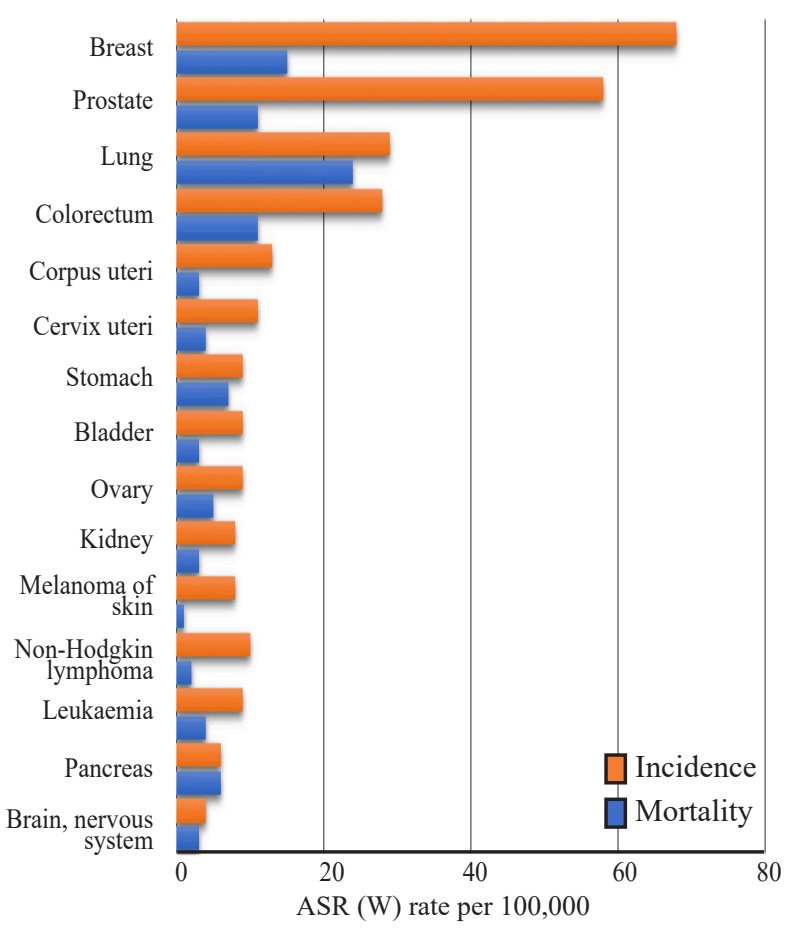

Figure 4. Estimated ASRs for incidence and mortality in Europe: both sexes [Source: Adapted and Modified from World Cancer Report, 2012]

\section{Cancer status in the neighboring countries}

In India, having a population of 1.2 billion, approximately one million new cancer patients are registered per year. A substantial proportion of these cancer cases are attributed to avoidable causes like tobacco use, infections etc ${ }^{27}$. Consolidated report of seven population based cancer registries (PBCRs) for the years 2001-2004 reported 89,297 new cancer cases, out of which 44,497 (49.83\%) were males and 44,800 (50.16\%) were females. Age adjusted rates (AAR) per 100,000 population in males ranged from 43.8 in Barshi to 114.9 in Delhi. Figures $6 \& 7$ show data reported by cancer registry at dehli in graphical form.

Three leading sites of cancer in males (with their relative proportion and AARs in parentheses) were lung (10.5\% and 12.8), larynx (5.9\% And 7.5) and tongue (5.4\% and 6.5). The leading cancer sites among females (Figure 7) were breast $(25.1 \%$ and 29.2$)$ followed by cervix uteri $(14.9 \%$ and 17.6$)$ and ovary $(7.2 \% \text { and } 8.0)^{28}$. Similarly, the cancer registry at Mumbai reported the three leading sites of cancer in males (with their relative proportion and AARs in parentheses) as lung (8.2\% and 8.9), mouth (7.7\% and 6.9) and larynx (5.8\% and 6.2). The leading cancer sites among females were breast $(27.5 \%$ and 27.5$)$ followed by cervix uteri $(13.0 \%$ and 13.0$)$ and ovary $(7.3 \% \text { and } 7.3)^{28}$.

In the neighboring country of Iran, the reported overall ASRs are 110.43 for men and 98.23 for women. Frequent cancers

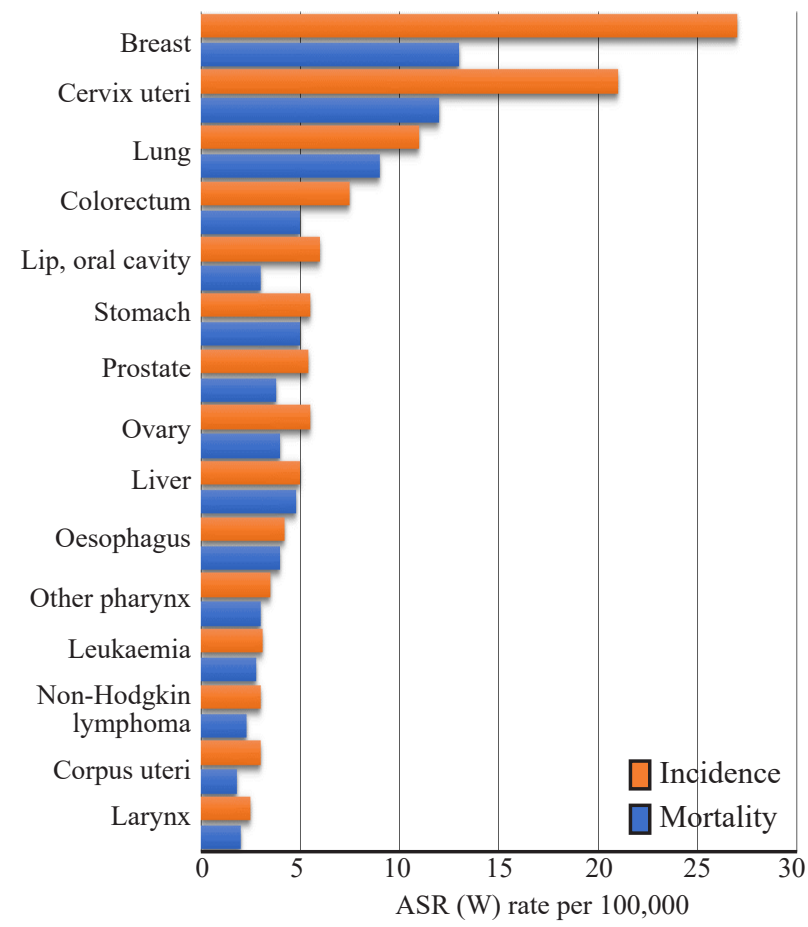

Figure 5. Estimated ASRs for incidence and mortality in South-East Asia: both sexes [Source: Adapted and Modified from World Cancer Report, 2012]

among males are those of esophagus, stomach, colon-rectum, bladder and leukemia. Cancers of breast, cervix uteri, stomach, esophagus, colon-rectum and are mostly seen in Iranian women ${ }^{1}$. In Iran cancer of stomach is the commonest cancer among males having an ASR 49.1 in certain areas. Adenocarcinoma prostate is the second one with an ASR of 15.6 (Tehran area). Among women, breast cancer is the commonest cancer having an ASR of 23.1.

In Sri Lanka, the top five cancer sites in males with respective ASRs are lip/ oral cavity/ pharynx (16.0), lungs (7.9), esophagus (5.7), colorectum (4.2) and lymphoma (3.9). Similarly in females the common cancers with respective ASRs are breast (20.6), cervix uteri (9.6), thyroid (6.4), ovary (6.7) and esophagus (6.4) $)^{31,32}$.

\section{Epidemiology of cancer in Pakistan}

In Pakistan there are over 1.4 million cancer patients. Each year around 139,000 new cancer cases are reported accounting for $10.73 \%$ cancer cases among SAARC countries. Every year reported cancer-related deaths are 101,600 contributing $11.45 \%$ to those of SARRC countries ${ }^{30}$. Areas comprising Pakistan revealed variable cancer incidences ${ }^{33-36}$. Shaukat Khanum Memorial Cancer Hospital and Research Centre (SKMCH \& RC) based cancer registry accumulated cancer data spread over 18-year duration from 1994 to 2012 (Table $1)^{33}$. In total 58,761 tumors including 55,974 malignant tumors were documented. In adults common malignancies 


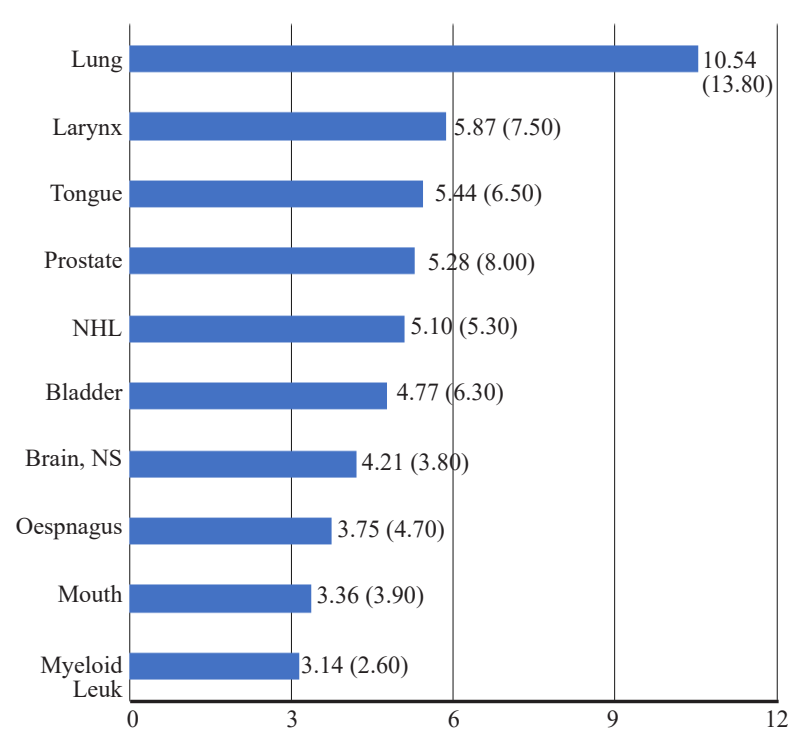

Figure 6. Leading cancer sites in males - Delhi (2001-2003) with age adjusted rates in parentheses [Source: Adapted and Modified from "Consolidated report of population based cancer registries 2001-2004"].

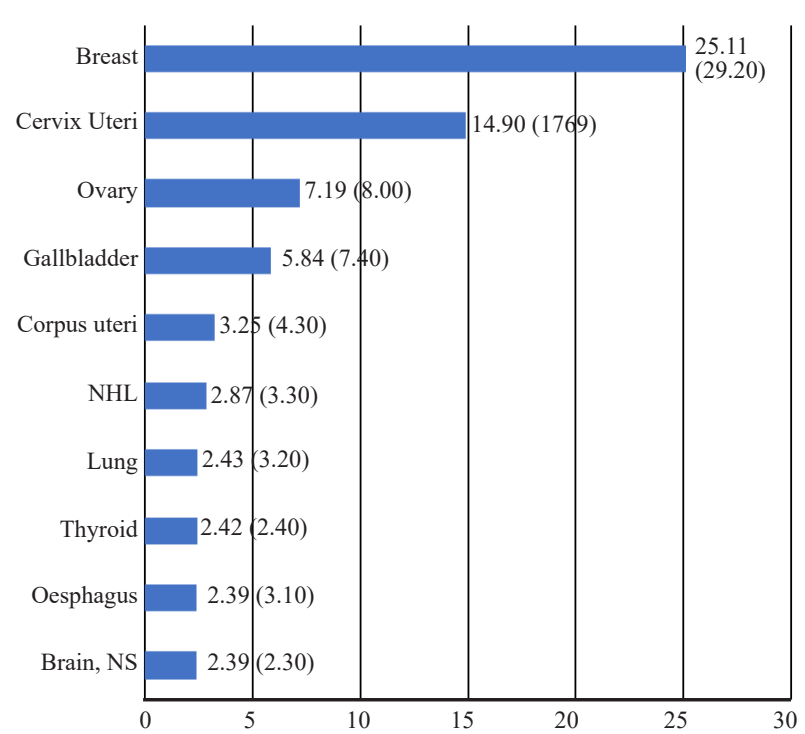

Figure 7. Leading cancer sites in females - Delhi (20012003) with ASRs [Source: Adapted and Modified from "Consolidated report of population based cancer registries 2001-2004"]

\begin{tabular}{|l|l|l|l|l|}
\hline \multicolumn{1}{|c|}{ Top 3 malignancies } & \multicolumn{1}{|c|}{ 1-Count (\%) } & \multicolumn{1}{c|}{ 2-Count (\%) } & \multicolumn{1}{c|}{ 3-Count (\%) } \\
\hline $\begin{array}{l}\text { All age-groups, both } \\
\text { male/female combined }\end{array}$ & $\begin{array}{l}\text { Ca breast } \\
11,853(21.18 \%)\end{array}$ & $\begin{array}{l}\text { Leukemia } \\
3,368(6.02 \%)\end{array}$ & $\begin{array}{l}\text { Lip \& Oral cavity } \\
3.336(5.96 \%)\end{array}$ & 55,974 \\
\hline $\begin{array}{l}\text { Adults } \\
(>18 \text { years) }\end{array}$ & $\begin{array}{l}\text { Ca breast } \\
11,848(23.81 \%)\end{array}$ & $\begin{array}{l}\text { Lip \& Oral cavity } \\
3,291(6.61 \%)\end{array}$ & $\begin{array}{l}\text { Liver/intrahepatic } \\
\text { bile ducts } 2,836(5.70 \%)\end{array}$ & 49,765 \\
\hline $\begin{array}{l}\text { Adult males } \\
(>18 \text { years })\end{array}$ & $\begin{array}{l}\text { Liver/intrahepatic bile } \\
\text { ducts } 2,076(8.66 \%)\end{array}$ & $\begin{array}{l}\text { Lip \& Oral cavity } \\
2,047(8.54 \%)\end{array}$ & $\begin{array}{l}\text { Non- Hodgkin's } \\
\text { lymphoma } 1,779(7.42 \%)\end{array}$ & 23,971 \\
\hline $\begin{array}{l}\text { Adult females } \\
(>18 \text { years })\end{array}$ & $\begin{array}{l}\text { Ca breast } \\
11,726(45.46 \%)\end{array}$ & $\begin{array}{l}\text { Ovary \& uterine adnexa } \\
1,524(5.91 \%)\end{array}$ & $\begin{array}{l}\text { Lip \& Oral cavity } \\
1,244(4.82 \%)\end{array}$ & 25,794 \\
\hline $\begin{array}{l}\text { Children } \\
(<18 \text { years })\end{array}$ & $\begin{array}{l}\text { Acute lymphoblastric } \\
\text { leukemia } 1,345(21.66 \%)\end{array}$ & $\begin{array}{l}\text { Hodgkin's lymphoma } \\
1,099(17.70 \%)\end{array}$ & $\begin{array}{l}\text { Non-Hodgkin's } \\
\text { lymphoma 694 }(11.18 \%)\end{array}$ & 6,209 \\
\hline
\end{tabular}

Table 1. Common three malignancies among both genders for the period 1994-2012 at SKMCH \& RC [Source: Modified and adapted from Badar and Mahmood, 2015]

were those of breast, lip, oral cavity, liver and intra-hepatic bile ducts, respectively. In adult males, in order of frequency common cancers were of liver/intrahepatic bile ducts, lip, oral cavity and Non-Hodgkin's lymphoma. Among adult females cancers of breast, ovary/ uterine adnexa, lip and oral cavity were common ${ }^{33}$.

Karachi Cancer Registry (KCR) registered cancers in Karachi South district for 1995 to 1997. ASRs of 139.11 and 169.5 per 100,000 were reported in males and females, respectively. Mean ages for males and females for all cancers were 51.2 years/ 50.0 years, respectively. In men ASRs for cancers of lung, oral cavity, urinary bladder and larynx were 21.3, 14.2, 9.0 and 8.8, respectively. In females reported ASRs cancers of breast, oral cavity and ovary were 53.1, 14.5 and 10.9, respectively. Similarly, ASRs for overall cancers registered between 1998 and 2000 were 179.0/100000 and 204.1/100000 for males and females. Mean ages for males and females for all cancers were 49.5 and 53.7 years, respectively. For this period, reported ASRs in males for cancers of lung, larynx and urinary bladder were 25.5, 11.8 and 9.9, respectively. ASRs in women for cancers of breast, oesophagus and cervix were 69.1, 8.6 and 8.6, respectively $^{37,38,39}$.

The Karachi Institute of Radiotherapy and Nuclear Medicine (KIRAN) is a cancer treatment facility that caters for patients from a large area of Sindh province in Pakistan. The cancer registry placed at KIRAN published malignancies reported between 2000 to 2008 (18,351 cases for 9-year-period). In male patients proportion of reported malignancies was: head and neck (32.6\%), gastrointestinal tract (6.9\%) and 
lymphomas (6.1\%). In females: breast cancer (38.2\%), head and neck cancer $(15.1 \%)$ and cervical cancer $(5.5 \%)^{8}$. Another hospital-based-registry at Aga Khan University Hospital (AHUH) has published retrospective data for 1989 to 1992. They reported 2632 malignant cases. Out of these common cancers in males were those of lung $(15.2 \%)$, head and neck $(10.6 \%)$ and lymphoma $(10.2 \%)$. In females, in order of frequency breast cancer (32.5\%), ovarian cancer $(7.9 \%)$ and cancer of gall bladder (7.7\%) were found to be common malignancies ${ }^{40}$.

\section{CONCLUSION:}

Cancers are the leading cause of death in technologically advanced countries while concomitant with economic development have been acquiring the status of a major public health problem in developing countries. This disease has assumed the status of the second commonest cause of death due to non-communicable diseases in developing countries like Pakistan. Review of current and old cancer epidemiological data proves that in future a definitive majority of all new cancer cases will occur in those countries that come under low and middle income category of WHO classification.

\section{REFERENCES:}

1. Ferlay J, Soerjomataram I, ErvikM, Dikshit R, Eser S, Mathers C, Rebelo M, Parkin DM, Forman D, Bray F et al. (2015). Cancer incidence and mortality worldwide: sources, methods and major patterns in GLOBOCAN 2012. Int J Cancer, 136(5):E359-86. doi: 10.1002//ijc.29210. Epub 2014 Oct 9.

2. Ferlay J, Soerjomataram I, Ervik M, et al. GLOBOCAN 2012 cancer incidence and mortality worldwide: IARC cancerbase No.11. Lyon, France: International Agency for Research on Cancer, 2013.

3. United Nations Population Division (UNDP). World population prospects, the 2010 revision. New York: United Nations. Available from: http://esa.un.org/wpp/index.htm. Last accessed on 15 September 2016.

4. Forman D, Bray F, Brewster DH, et al., eds. Cancer incidence in five continents, vol X (electronic version). Lyon: IARC, 2013. Available at: http://ci5.iarc.fr. Last accessed on $10^{\text {th }}$ December, 2014.

5. World Health Organization (WHO) Databank. Health statistics and information systems, Geneva, Switzerland: WHO. Available at: http://www.who.int/healthinfo/statistics /mortality_rawdata/en/. Last accessed July, 2014.

6. United Nations Development Programme. Human development report, 2013. Available at: http://hdr.undp.org/en. Last accessed 15th March, 2014.

7. Ferlay J, Steliarova-Foucher E, Lortet-Tieulent J, et al. Cancer incidence and mortality patterns in Europe: estimates for 40 countries in 2012. Eur J Cancer 2013;49:1374-403.

8. Parkin DM, Bray F, Feraly J, et al. Global Cancer Statistics. CA Cancer J Clin, 2002; 55:74-108.

9. Boyle P, Ferlay J. Cancer incidence and mortality in Europe. Ann Oncol, 2005;481-8.

10. Banoczy J, Squier C. Smoking and disease. Eur J Dent Edu, 2004;8(Suppl 4):7-10.
11. Wingo PA, Reis LA, Giovino GA, et al. Annual report to the nation on the status of cancer, 1973-1996, with a special section on lung cancer and tobacco smoking. J Natl Cancer Inst, 1999;91:675-90.

12. Farley J, Shin H, Bray F. GLOBOCAN 2008 v1.2, cancer incidence and mortality worldwide: IARC cancer base no. 10. Lyon (France). International Agency for Research on Cancer; 2010.2012.

13. Parkin DM, Bray F, Ferlay J, Pisani P. Estimating the world cancer burden: Globocan 2000. Int J Cancer, 2001; 15;94(2):153-6.

14. Ferlay J, Pisani P, Parkin DM. GLOBOCAN 2002. Cancer incidence, mortality and prevalence worldwide. IARC Cancer Base (2002 estimates). Lyon: IARC Press; 2004.

15. Parkin DM. The evolution of the population-based cancer registry. Nat Rev Cancer 2006; 6:603-12.

16. Pisani P, Parkin DM, Ferlay J. Estimates of the worldwide mortality from eighteen major cancers in 1985. Implications for prevention, and projections of future burden. Int J Cancer 1993; 55:891-903.

17. Mathers $\mathrm{C}, \mathrm{Ma}$ Fat $\mathrm{D}$, Inoue $\mathrm{M}$, et al. Counting the dead and what they died from: an assessment of the global status of cause of death data. Bull World Health Org 2005; 83:171-7.

18. Curado MP, Edwards B, Shin HR, et al., eds. Cancer incidence in five continents, vol. IX. Lyon: IARC, 2007. IARC Scientific Publications No. 160.

19. Ferlay J, Shin HR, Bray F, et al. Estimates of world burden of cancer in 2008: GLOBOCAN 2008. Int J Cancer, 2010; 127:2893-917.

20. Bray F. Transitions in human development and the global cancer burden. In: Wild CP, Stewart B, eds. World cancer report 2014. Lyon: International Agency for Research on Cancer, 2014.

21. Ferlay J, Soerjomataram I, Ervik M, et al. GLOBOCAN 2012 cancer incidence and mortality worldwide: IARC cancerbase No. 11. Lyon, France: International Agency for Research on Cancer, 2013.

22. Sankaranrayanan R, Swaminathan R, Lucas E. Cancer survival in Africa, Asia, the Caribbean and Central America (SurvCan). IARC Scientific Publications vol. 162. ISBN 978-92-8322162-3. Lyon: International Agency for Research on Cancer, 2011.

23. de Martel C, Ferlay J, Franceschi S, et al. Global burden of cancers attributable to infections in 2008: a review and synthetic analysis. Lancet Oncol 2012; 13:607-15.

24. Gulland, A. (2014). Global cancer prevalence is growing at "alarming pace," says WHO. BMJ, 348, g1338. http://dx.doi. org/10.1136/bmj.g1338

25. American Cancer Society. (2016). Cancer Facts \& Figures. Atlanta: American Cancer Society.

26. Jensen OM, Estève J, Møller H, et al. Cancer in the European Community and its member states. Eur J Cancer 1990; 26:1167256

27. Mallath, M.K., Taylor, D.G., Badwe, R.A., Rath, G.K., Shanta, V., Pramesh, C.S. et al. (2014). The growing burden of cancer in India: epidemiology and social context. The lancet Oncology, 15(6), e205-e212.

28. Consolidated report of population based cancer registries 2001-2004. National Cancer Registry Programme: Accessed 
Global And Regional Cancer Epidemiology: According To World Cancer Report 2012 And Others.

April 29, 2016, from, http://www.icmr.nic.in/ncrp/cancer reg.htm

29. Kolahdoozan S, Sadjadi A, Radmard AR, Khademi H. Five Common Cancers in Iran: Mini Review. Arch Iran Med 2010; 13 (2): $143-146$

30. Fallah M. Cancer Incidence in Five Provinces of Iran: Ardebil, Gilan, Mazandaran, Golestan and Kerman, 1996 - 2000. Academic dissertation. Accessed at - http://urn.fi/urn:isbn:978951-44-6876-6.

31. National Cancer Control Programme. 2012. Cancer Incidence Data: Sri Lanka Year 2006. Retrieved from https:/www.nccp.health.gov.lk/images/PDF_PUBLICATIO NS/CancerRegistry2006.pdf

32. Noronha, V., Tsomo, U., Jamshed, A., Hai, M., Wattegama, S., Baral, R., et al. (2012). A fresh look at oncology facts on South Central Asia and SAARC countries. S Asian J of Can, 1(1), 1-4.

33. Badar, F. \&Mahmood, S. (2015). Hospital-Based Cancer Profile at the Shaukat Khanum Memorial Cancer Hospital and Research Centre, Lahore, Pakistan. Journal of College of Physicians and Surgeons Pakistan, 25(4), 259-263.
34. Malignant tumors - a report of multi centre study 1982. Pakistan Medical Research Council Pakistan.

35. The Punjab cancer registry [Internet]. 2016. [cited 2016 Apr.25]. Available from: http://punjabcancerregistry.org.pk/

36. Malik IA, Khan WA. Pattern of malignant tumors observed in a university hospital: A retrospective analysis. Journal of Pakistan Medical Association, 1998; 48: 120-122.

37. Bhurgri, Y., Bhurgri, A., Nishter, S., Ahmed, A., Usman, A., Pervaiz, S., et al. (2006). Pakistan - Country Profile of Cancer and Cancer Control 1995-2004. J Pak Med Assoc, 56(3), 124130 .

38. Bhurgri Y. Karachi Cancer Registry Data - Implications in NCCP Pakistan. Asian Pac J Cancer Prev, 2004; 5:86-91.

39. Bhurgri Y, Bhurgri A, Hassan SH, Zaidi SMH, Sankaranarayanan R, et al. Cancer Incidence in Karachi, Pakistan: First Results from Karachi Cancer Registry. (2000). Int Cancer, 2000; 85:325-329.

40. Malik, I.A., \& Khan, W.A. (1998). Pattern of malignant tumors observed in a university hospital: A retrospective analysis. J Pak Med Assoc, 48, 120-122. 